US exposes same old faults

\section{Washington}

As visions of levitated trains and cheap electricity from superconducting generators have faded, research into hightemperature superconductivity, now four years old, has settled in for the long haul. But the initial ballyhoo caught the imagination of politicians as well as the public in the United States, and coming along with fears of Japan's rising technical prowess, it propelled the notion that hightemperature superconductivity could be the vehicle for new policies that might help turn basic research into marketable products. Now, says a report from the congressional Office of Technology Assessment (OTA), the research is going well but the policy derailed some time ago.

Total spending on high-temperature superconductivity research in the United States and Japan is about the same. In 1989 , the US government spent $\$ 130$ million, and the Japanese about $\$ 70$ million, but for spending by industry the figures are almost reversed. The quality of the research seems to be on a par: the OTA report describes US research as "second to none", while in the March 1990 issue of Science Watch two of three 'hottest' (most cited) papers in physics concern high-temperature superconductivity and both from Japan. But although equal now, differences are set to emerge.

Almost half the high-temperature superconductivity money from the US government has gone to the Department of Defense, while Japan's spending is all aimed at commercial, not military application. In addition, the remainder of the US federal research support goes predominantly to the national laboratories, which have a poor track record in technology transfer to industry.

In Japan, a big success by MITI (Ministry of International Trade and Industry) was the establishment in 1988 of ISTEC (the International Superconductivity Technology Center), a consortium of industrial contributors (including a handful of US and European companies) who each pay about $\$ 100,000$ annually to support high-temperature superconductivity research. Although ISTEC is the kind of government-led effort that generally inspires fear and envy in the United States, the OTA report plays down its significance, arguing that it is occupied entirely with basic research of the kind that is adequately supported, but in different ways, by the US goverment.

The bigger threat to US supremacy, according to OTA, is the much greater level of support by Japanese industry, and the more patient thinking that lies behind it. In a survey of US and Japanese industries doing high-temperature superconductivity research, US respondents said, on average, that they expected to see the first commercial products on the market in 1992, whereas the Japanese companies saw the likely date as 2000 . Given the fairly equal base of research in the two countries, the difference is presumed to reflect more favourably on Japanese persistence than US optimism.

David Lindley

High-Temperature Superconductivity in Perspective: OTA-E-440, April 1990

\title{
Fuzzy computers go home
}

\section{Tokyo}

JAPANESE housewives are about to have their first encounter with fuzzy computing. Matsushita Electric Industrial Co. has announced the launch of two new products intended to ease household cleaning chores, the fuzzy vacuum cleaner and the fuzzy washing machine. These are the first consumer products to emerge from a huge effort by Japanese industry to develop fuzzy computing technology.

Fuzzy computing is based on fuzzy set theory, developed by L. A. Zadeh of the University of California in the 1960s. Whereas conventional computers operate on Yes/No logic, fuzzy computers form conclusions from imprecise data (such as 'faster' or 'stronger') by giving such input a value somewhere in the continuum between zero and one.

Matsushita's fuzzy washing machine, affectionately called 'Aisaigo (beloved wife) Day Fuzzy', comes equipped with two 'eyes' (optical sensors) which can detect the quantity of clothes and the quality and quantity of their dirt. A fuzzy microcomputer then selects the most suitable of 600 possible cycles to wash the clothes. The fuzzy vacuum cleaner assesses the amount of dust and the nature of the floor and adjusts the suction power of the cleaner accordingly. Both machines are intended to allow housewives "to enjoy easier, more comfortable lives", says a company press release.

Matsushita is just one of many Japanese companies involved in developing fuzzy computing. Last year, MITI set up the Laboratory for International Fuzzy Engineering Research (LIFE) with the backing of 42 companies, including steel, automobile, electronics, transportation, electric utility and security companies. And the Tokyo stock market is a future target for fuzzy control through fuzzy programme trading.

David Swinbanks
Banking on greener legislation

Washington

MORE than 200 legislators from 42 countries outlined a broad legislative strategy to combat global environmental problems at a three-day meeting in Washington last week. Hosted by the US Congress, the Interparliamentary Conference on the Global Environment was intended to coordinate environmental legislation around the world. The lawmakers called for a "global Marshall plan" to help developing countries deal with their environmental problems without undermining their economic growth.

They also proposed a "green common market" through which industrialized nations could share technology and agricultural techniques that can reduce greenhouse gas emissions. A "bank for sustainable development" could lend money to developing countries for projects that would not harm the environment. The legislators also called for a 50 per cent reduction in greenhouse gases by the year 2010. Although the conference delegates do not make policy for their governments, several said they would soon introduce legislation in line with the conference resolutions.

G. Christopher Anderson

\section{GLOBAL WARMING}

\section{Majority verdict on temperature rise Washington}

Most climate change scientists believe that a global temperature rise of 2 degrees Celcius or more over the next hundred years is a better than even chance, according to an international survey released last week by the Global Environmental Change Report, an Arlington, Massachusettsbased newsletter. But a majority of the scientists who replied to the survey admitted that scientific evidence currently available cannot yet prove the case.

The newsletter sent out 1,500 questionnaires to a random sample of scientists studying climate change. Of the $\mathbf{3 3 0}$ that returned the survey, 65 per cent believe that the two-or-more degree temperature rise is $50-100$ per cent likely; 31 per cent think it has less than a $\mathbf{5 0}$ per cent chance.

Over 93 per cent of the scientists questioned believe that some significant warming will occur over the next century. Although 76 per cent think that humaninduced greenhouse warming is already occurring, only 41 per cent believe that science can substantiate that opinion. However, nearly 90 per cent think that countries should take immediate action to reduce $\mathrm{CO}_{2}$ emissions, despite the scientific uncertainties that remain.

G. Christopher Anderson 